\title{
Gastric emptying and gastro-oesophageal reflux in preterm infants
}

\author{
AK Ewer, GM Durbin, MEI Morgan, IW Booth
}

\begin{abstract}
Gastro-oesophageal reflux is common in preterm infants, but the role of gastric emptying as a causal factor has not been studied before. Gastric emptying was therefore measured in 19 healthy preterm infants (median gestational age 32 weeks) while concurrently measuring 24 hour lower oesophageal pH, using an antimony pH electrode, positioned manometrically. Real time ultrasonic images of the gastric antrum were obtained, and measurements of antral cross-sectional area (ACSA) were made immediately before a nasogastric feed and then during subsequent gastric emptying until ACSA returned to its pre-feed value. Half emptying time (50\% $\triangle$ ACSA) was calculated as the time taken for the ACSA to fall to half the maximal postprandial increment.

Mean (SEM) reflux index for the group was $11.9(2.0) \%$; number of reflux episodes per 24 hours: 15.4 (1.7); and number of reflux episodes longer than five minutes 5.5 (0.8). Average half emptying times for an individual infant were: median (range) 46 (18-105) minutes. There was no association between gastric emptying rates and any of the indices of gastro-oesophageal reflux, either during the entire 24 hour period for which the lower oesophageal pH was recorded, or in the postprandial periods after the feeds which were studied ultrasonically. Gastro-oesophageal reflux was also unrelated to feed volume and feed type.
\end{abstract}

Asymptomatic gastro-oesophageal reflux is common in preterm infants, but gastric emptying time is not a determinant of it. Inappropriate relaxation of the lower oesophageal sphincter or abnormal oesophageal motility offer more plausible explanations.

(Arch Dis Child 1996;75:F117-F121)

Keywords: gastric emptying, gastro-oesophageal reflux, preterm infants.

Gastro-oesophageal reflux is common in preterm infants ${ }^{1}$ and may cause apnoea, ${ }^{1}$ aspiration pneumonia, ${ }^{2}$ and chronic lung disease. ${ }^{3}$ Despite its associated morbidity, the determinants in this group of infants have not been clearly defined.

There are several potential determinants of gastro-oesophageal reflux: immature oesophageal peristalsis; reduced lower oesophageal sphincter pressure; inappropriate relaxation of the lower oesophageal sphincter and delayed gastric emptying. Newell et al showed that resting lower oesophageal sphincter pressure increases with maturity, but that there was no association between resting sphincter pressure and gastro-oesophageal reflux.

Previous studies examining the relation between delayed gastric emptying and gastrooesophageal reflux in adults and children have given equivocal results. Several groups have detected an association between delayed gastric emptying and gastro-oesophageal reflux in adults, ${ }^{5-7}$ while others have failed to do so. ${ }^{89}$ Some studies have shown an association in infants and older children. ${ }^{10-15} \mathrm{Di}$ Lorezo et al $^{14}$ failed to demonstrate any such association in children under 3 years of age. No study of neonates has shown a correlation. ${ }^{14}{ }^{15}$ Jolley et al examined gastric emptying of clear fluids in infants and children and failed to demonstrate an association between rate of emptying and reflux. ${ }^{16}$ To our knowledge, a combined study of gastric emptying and gastro-oesophageal reflux in preterm infants has not been undertaken, probably because of previous methodological constraints.

Recent work in our department has confirmed that both prolonged lower oesophageal $\mathrm{pH}$ monitoring, using an antimony crystal electrode, and measurement of gastric emptying are now feasible in low birthweight neonates. ${ }^{1718}$ Using these novel techniques, we have recently shown that gastrooesophageal reflux is common ${ }^{1}$ and that feed type has a major impact on gastric emptying in this group of patients. ${ }^{18}$ However, the association between gastro-oesophageal reflux and delayed gastric emptying remains uncertain. We therefore carried out a study in which we measured gastric emptying and gastrooesophageal reflux in a group of healthy preterm infants. The aim of the study was to evaluate the role of gastric emptying as a determinant of gastro-oesophageal reflux.

\section{Methods}

The study was carried out on the Regional Neonatal Intensive Care Unit at Birmingham Maternity Hospital. Infants were entered into the study if they fulfilled the following criteria: preterm delivery (less than 37 weeks of gestation); absence of, or complete recovery from, respiratory illness; no evidence of gastrointestinal disease; no drug treatment other than vitamins and minerals; receiving full enteral feeds via a nasogastric tube at a minimum of $150 \mathrm{ml} / \mathrm{kg} /$ day, with an interval of at least 3 hours between feeds. 
Nineteen consecutive infants (11 girls, 8 boys) who fulfilled the entry criteria and for whom consent was obtained, were recruited. Median (range) gestation of the group was 32 (29-34)weeks; birthweight 1620 (980-2370) g, and postnatal age at the time of study 21 (7-37) days. Seventeen infants were appropriately grown for gestational age at birth; two infants had a birthweight below the 10th centile for gestational age. No infant had symptomatic reflux before the study.

\section{FEEDING}

Two gastric emptying studies were performed on each of the 19 infants during the 24 hour period in which lower oesophageal $\mathrm{pH}$ was recorded. Each infant received bolus nasogastric feeds of the same volume of milk during each study. Median daily feed volume was 150 $\mathrm{ml} / \mathrm{kg} /$ day (range $150-200$ ) given at 3 or 4 hourly intervals. Median feed volume was 40 $\mathrm{ml} /$ feed (range 25-70), equivalent to $21 \mathrm{ml} / \mathrm{kg}$ ) feed (17-29). Feeds were administered over a median period of 7.5 minutes (range 2-16). Nine infants received a whey-based term formula (Cow and Gate Premium), eight infants received a preterm formula (Cow and Gate Low Birthweight Formula), one infant received a combination of maternal breast milk and term formula, and one infant received breast milk only.

\section{ASSESSMENT OF GASTRIC EMPTYING}

Gastric emptying was estimated using a previously described ultrasonic method. ${ }^{17}{ }^{18}$ The method uses gastric antral transit as a proxy for gastric emptying, and measures ultrasonically, the changes in the cross-sectional area of the gastric antrum which occur during instillation and following a feed.

Real time ultrasonic images of the same longitudinal section of the gastric antrum were obtained with the infant in the right lateral position, using the vertebral bodies and the aorta, at the level of the superior mesenteric artery, as constant anatomical landmarks. A Hewlett Packard ultrasound imaging system (model 77020A) with a $5 \mathrm{MHZ}$ sector scanning probe (model 21210A0), held perpendicular to the anterior abdominal wall, just below the xiphisternum, produced satisfactory images during all studies. The ACSA was measured using a steerable cursor and integral software.

The stomach was aspirated before a feed to remove residual air or milk. ACSA was measured before the feed, as soon as the feed was completed, and sequentially at roughly 10 minute intervals until it returned to its pre-feed value. We defined half emptying time $(50 \% \Delta$ ACSA) as the time taken for ACSA to fall by half of the maximal change seen during gastric filling. All scans and measurements were performed by the same investigator (AKE).

ASSESSMENT OF GASTRO-OESOPHAGEAL REFLUX A well validated intra-oesophageal $\mathrm{pH}$ monitoring system utilising an monocrystalline antimony $\mathrm{pH}$ electrode was used over a 24 hour period (Digitrapper Mark II solid state re- corder, $1.5 \mathrm{~mm}$ diameter paediatric $\mathrm{pH}$ electrode, Synectics Medical Ltd). The electrode was bonded $5 \mathrm{~cm}$ from the end of a 3.5 Charrière gauge umbilical catheter (external diameter $1.2 \mathrm{~mm}$ ) with a PVC solvent (cyclohexanone) mixed with PVC shreds. The umbilical catheter was then connected to a continuous perfusion manometric system which has been described before. ${ }^{4}$ This system was perfused at $3 \mathrm{ml} /$ hour with sterile dextrose/ saline ( $4 \%$ dextrose, $0.18 \%$ saline) via a Vickers IP3 high pressure pump connected to a stainless steel capillary tube (internal diameter $0.2 \mathrm{~mm}$ ) connected to a pressure transducer (Hewlett Packard type 1280). The single end opening umbilical catheter was then connected to the transducer by a $100 \mathrm{~cm}$ PVC extension tube (Vygon 1151.10). Dissolved gases were removed from the perfusate before use by creating a partial vacuum. The output from the transducer was received by an isolated pressure amplifier (Hewlett Packard type 78205C) and plotted on an Ormed 4 channel chart recorder (type MX412) running at $1 \mathrm{~mm} / \mathrm{second}$

The position of the lower oesophageal sphincter was determined using this system, and the end of the catheter then advanced into the stomach, leaving the $\mathrm{pH}$ electrode $2 \mathrm{~cm}$ above the lower oesophageal sphincter. The umbilical catheter was then used as a feeding tube for the duration of the study. Radiology was not used.

A reflux episode was defined as a lower oesophageal $\mathrm{pH}$ of $<4.0$ for 15 seconds or longer. Reflux index was defined as the percentage of study time during which lower oesophageal $\mathrm{pH}$ was $<4.0$. The number of reflux episodes and the number of reflux episodes greater than five minutes were also recorded. Calibration of the $\mathrm{pH}$ electrode was performed before and after each study using standard buffer solutions of $\mathrm{pH} 1.0$ and 7.0 (Synectics Medical Ltd). No drift was noted.

Informed parental consent was obtained in each case and the protocol was approved by the local research ethical committee.

Correlation coefficients $r$ were calculated to define the association between gastric emptying rates and individual reflux indices.

\section{Results}

GASTRIC EMPTYING

The ultrasonic technique was well tolerated. No infant vomited or appeared distressed during the studies. Two feeds were studied in each infant, making a total of 38 recordings. Only one infant received different milk types during the two gastric emptying studies and all others received the same milk. The median half emptying times ( $50 \% \triangle \mathrm{ACSA}$ ) for all gastric emptying studies $(n=38)$ was 44 minutes (range 15-114). Taking the mean value for the two studies performed on an individual $(n=19)$, the median was 46 minutes (range 18.5-105). The mean (SEM) difference between half emptying times of feeds within an individual baby was 17 (3.6) minutes. There was a slight trend towards faster gastric emptying with increasing postnatal age (Pearson correlation coefficient -0.6), 
Table 1 Mean (SEM) postprandial reflux indices for two feeds studied in each infant $(n=38)$

\begin{tabular}{|c|c|c|c|c|c|c|c|c|}
\hline \multirow[b]{3}{*}{ Reflux index (\%) } & \multicolumn{8}{|c|}{ Postprandial time (minutes) } \\
\hline & $0-30$ & $30-60$ & $60-90$ & $90-120$ & $120-150$ & $150-180$ & $180-210$ & $210-240$ \\
\hline & $2.2(1.2)$ & $5.5(3.1)$ & $3.2(1.6)$ & $12.3(4.5)$ & $19.9(5.6)$ & $10.8(4.4)$ & $5.4(3.8)$ & 0 \\
\hline Number of reflux episodes & $0.16(0.07)$ & $0.18(0.09)$ & $0.21(0.09)$ & $0.45(0.12)$ & $0.37(0.08)$ & $0.24(0.08)$ & $0.14(0.1)$ & 0 \\
\hline Number of reflux episodes $>5$ mins & $0.05(0.04)$ & $0.1 \quad(0.05)$ & $0.05(0.03)$ & $0.18(0.06)$ & $0.26(0.07)$ & $0.16(0.06)$ & $0.14(0.1)$ & 0 \\
\hline
\end{tabular}

but the study was not specifically designed to examine this.

Mean gastric half emptying times were longer and feed volumes greater for term formula than for preterm formula. The number of studies for term formula were 19 ; mean (SEM) half emptying time 64 (7.1)minutes; feed volume $48(3.0) \mathrm{ml}$. There were 16 studies for preterm formula; mean half emptying time 34 (4.9)minutes; feed volume $32(2.7) \mathrm{ml}$. Only two infants received breast milk (number of studies $=3$ ) and mean half emptying times were 44 (4.7) minutes; feed volume 42 (1.7) $\mathrm{ml}$.

\section{GASTRO-OESOPHAGEAL REFLUX}

The position of the lower oesophageal sphincter was detected in each infant using the manometric system. The umbilical catheter was adequate as a feeding tube and did not require replacement during any of the studies.

Gastro-oesophageal reflux was common: mean (SEM) reflux index was $11.9(2.0) \%$; number of reflux episodes per 24 hours 15.4 (1.7); and number of reflux episodes longer than 5 minutes per 24 hours $5.5(0.8)$. Only one infant, who had the highest reflux index (39.3\%), had symptoms (small vomits) during the study period.

There was no correlation between gastric half emptying times and any of the indices of gastro-oesophageal reflux over 24 hours. Pearson correlation coefficients for average half emptying times and reflux index, number of reflux episodes, and reflux episodes longer than five minutes were $0.057,0.02$, and -0.01 , respectively. As gastric emptying rates were measured for only two feeds during the 24 hours over which lower oesophageal $\mathrm{pH}$ was recorded, we performed an analysis of reflux indices for consecutive 30 minute intervals during each postprandial period after each of the study feeds. Postprandial period was defined as the time between administration of the study feed and administration of the next feed.

Gastro-oesophageal reflux was most common between 120 and 150 minutes after the feed (table 1), but there was no correlation between half emptying times and postprandial reflux. Pearson correlation coefficients for half emptying time of the feed and postprandial reflux index, number of reflux episodes, and number of episodes longer than five minutes were $0.15,0.30$, and 0.33 , respectively. In eight infants the total postprandial reflux index was the same for each feed despite a difference in emptying rates between the two feeds. In five infants a higher postprandial reflux index was noted in the slower emptying feed compared with the more rapidly emptying feed.

There was no correlation between feed volume and reflux index (Pearson correlation coefficient $=0.05$ ), and no difference between postprandial reflux index for preterm and term formula. The postprandial reflux index following the three breast milk feeds was zero in each case. But the small number of breast milk feeds studied (three) prevents any meaningful conclusion from being drawn. Moreover, the reflux index for the 24 hour study period in the one patient who received breast milk only was $11.1 \%$ (table 2). There was no clear correlation between reflux index and postnatal age (Pearson correlation coefficient 0.37 ).

\section{Discussion}

Our data confirm that gastro-oesophageal reflux is common in preterm infants. It is considered a potent cause of apnoea in this group and may contribute to chronic lung disease through recurrent aspiration of milk. Symptoms of reflux may also delay or prevent successful enteral feeds and this in turn may have adverse effects on growth and subsequent neurodevelopmental outcome. ${ }^{19}$ The investigation of any potential determinants of gastrooesophageal reflux in this group, therefore, has important implications for the management of these infants.

An association between significant gastrooesophageal reflux and delayed gastric emptying has been described in some adults and older children; other studies, however, have failed to show any correlation. Although there is some evidence that delayed gastric emptying may be a precipitating factor in gastrooesophageal reflux in adults, the evidence in children, particularly infants, is much less clear.

Our data show that although gastric emptying rates are very variable in this group, depending on feed type and volume, slower emptying does not predispose to increased

Table 2 Gastric emptying and reflux indices according to feed type (data expressed as mean (SEM))*

\begin{tabular}{lllllll}
\hline Feed type & $\begin{array}{l}\text { Subjects } \\
(n)\end{array}$ & $\begin{array}{l}\text { Feed volume } \\
(\mathrm{ml})\end{array}$ & $\begin{array}{l}\text { GE time } \\
\text { (minutes) }\end{array}$ & $\begin{array}{l}\text { Reflux index / } \\
24 \text { hours (\%) }\end{array}$ & $\begin{array}{l}\text { No RE / 24 hours } \\
\text { No RE }>\end{array}$ & $\begin{array}{l}5 \text { minutes / } \\
24 \text { hours }\end{array}$ \\
\hline Term formula & 9 & $49(3.3)$ & $62(7.7)$ & $10.5(3.7)$ & $15(3.2)$ & $5(1.1)$ \\
Preterm formula & 8 & $32(2.8)$ & $34(4.9)$ & $11.4(2.7)$ & $15(2.6)$ & $6(1.5)$ \\
Breast milk & 1 & $40(-)$ & $45(-)$ & $11.1(-)$ & $19(-)$ & $8(-)$
\end{tabular}

^ Data from the patient who received both breast and formula milk have been omitted 
gastro-oesophageal reflux. Likewise, we were unable to demonstrate a difference in degree of gastro-oesophageal reflux with different feed type. Previous authors have noted differences in reflux between infants fed formula milk and breast milk, ${ }^{20}$ but not between caseinpredominant, whey-hydrolysate or soy formula. ${ }^{21}$ Although no difference was noted in our study, it was not specifically designed to investigate this factor and the number of infants receiving breast milk was very low.

We noted a high mean reflux index of $11.9 \%$ in our study group. This figure is higher than that reported by Newell et al in their study of very low birthweight infants. ${ }^{1}$ There are several possible reasons for this difference. Four infants in our study group had reflux indices of $20 \%$ or greater and this considerably increased the mean reflux index for the entire group. Our study group also comprised larger, more mature infants who were receiving larger feed volumes at less frequent intervals ( 3 or 4 hourly). None of our study group was ventilated and they were, by definition, healthy infants. Mechanical ventilation reduces the degree of gastro-oesophageal reflux up to threefold. ${ }^{21}$ Sicker infants are also more likely to receive feeds at more frequent intervals, and the buffering effect of milk in the stomach ${ }^{22}$ may contribute to a reduction in acid reflux, particularly in infants who are on hourly or continuous feeds. The fact that reflux was more common in the third postprandial hour is consistent with this.

The gastric emptying times recorded in our group were consistent with our previously reported data. ${ }^{18}$ Again, there was a large variability among individuals within the group. We have shown that emptying times are related to feed type and volume and this effect was also seen in this group. Although there is a large variability among infants, gastric emptying times within an individual are reproducible using this method, ${ }^{18}$ but some natural physiological variability still exists. In this study we measured gastric emptying times for only two feeds during the study period. This may not accurately reflect the average emptying time for gastric emptying during the 24 hours. However, careful analysis of the postprandial periods (overall, and in segments) of the two feeds studied showed no correlation between gastric emptying and gastro-oesophageal reflux.

Newell $e t a l^{*}$ have shown that even very premature infants have a resting lower oesophageal sphincter pressure, and that this pressure increases with increasing postconceptional age, but the group was unable to demonstrate any clear association between lower oesophageal sphincter pressure and degree of gastrooesophageal reflux. ${ }^{1}$ This makes the possibility of inappropriate relaxation of the sphincter or abnormal oesophageal motility being causal factors in the severity of gastro-oesophageal reflux more likely. Inappropriate sphincter relaxation or spontaneous relaxation in the absence of a preceding peristaltic sequence has been described in adults ${ }^{24}$ and children ${ }^{25-27}$ with severe reflux. Manometric studies have shown disordered motor activity in such cases. Omari et al have recently investigated this phenomenon in healthy preterm infants, using a miniature sleeve sensor to monitor oesophageal motility. ${ }^{28}$ They showed that preterm infants have pronounced non-peristaltic oesophageal motility, and postulate that this may contribute to poor clearance of refluxed materials. Several transient relaxations of the lower oesophageal sphincter were also noted. These observations may elucidate the precise aetiology of gastrooesophageal reflux in preterm infants, but further studies are necessary.

In summary, we have shown that gastrooesophageal reflux is unrelated to gastric emptying time in preterm infants using techniques which were well tolerated. Further studies continuously measuring lower oesophageal sphincter pressure, oesophageal motility, and $\mathrm{pH}$ are required to define precisely the association between oesophageal motility, lower oesophageal sphincter pressure, and gastrooesophageal reflux.

Dr Andrew Ewer was the holder of a West Midlands Regional Health Authority Sheldon Research Training Fellowship. We are indebted to the nursing staff of the Regional Neonatal Intensive Care Unit and the Transitional Care Ward at Birmingham Maternity Hospital for their help and cooperation, Birmingham Maternity Hospital for their help and cooperation,
to Dr SJ Newell for his helpful advice, and to Mr GW Hollins and P Williams (BMH Medical Physics) for technical support.

We also thank the Children's Research Fund, Liverpool, for their generous support.

Part of this work was presented at the 4th Joint Meeting of ESPGAN and NASPGN in October 1994.

1 Newell SJ, Booth IW, Morgan MEI, Durbin GM, McNeish AS. Gastro-oesophageal reflux in preterm infants. Arch Dis Child 1989;64:780-6.

2 Wharton BA, Bower BD. Immediate or later feeding for premature babies? Lancet 1965;ii:969-72.

3 Herbst JJ, Minton SD, Book LS. Gastro-oesophageal reflux causing respiratory distress and apnea in newborn infants. f Pediatr 1979;95:763-68.

4 Newell SJ, Sarkar PK, Durbin GM, Booth IW, McNeish AS. Maturation of the lower oesophageal sphincter in the preterm baby. Gut 1988;29:167-72.

5 Cunningham KM, Hororwitz M, Ridell PS, et al. Relations among autonomic nerve dysfunction, oesophageal motility, and gastric emptying in gastro-oesophageal refiux disity, and gastric emptying in

6 Maddern GJ, Chatterton BE, Collins PJ, Horowitz M, Shearman DJC, Jamieson GG. Solid and liquid gastric emptying in patients with gastro-oesophageal reflux. $\mathrm{Br} f$ Surg 1985;72:344-7.

7 Velasco N, Hill LD, Gannan RM, Pope CE. Gastric emptying and gastro-oesophageal reflux. Effects of surgery and correlation with esophageal motor function. Am f Surg 1982;144:58-61.

8 Schwizer W, Hinder RA, DeMeester TR. Does delayed gastric emptying contribute to gastro-oesophageal reflux distric emptying contribute to gastro-

9 Shay SS, Eggli D, McDonald C, Johnson LF. Gastric emptying of solid food in patients with gastro-oesophageal reflux. Gastroenterology 1987;92:459-65.

10 Hillemeier AC, Lange R, McCallum R, Seashore J, Gryboski J. Delayed gastric emptying in infants with gastro-oesophageal reflux. F Pediatr 1981;98:190-3.

11 Carroccio A, Iacono G, $\mathrm{Li}$ Voti G, et al. Gastric emptying in infants with gastro-oesophageal reflux. Ultrasound evalua-
tion before and after cisapride administration. Scand $\mathcal{F}$ tion before and after cisapride

12 Papaila JG, Wilmot D, Grosfeld JL, Rescoria FJ, West KW, Vane DW. Increased incidence of delayed gastric emptying in children with gastro-oesophageal reflux. Arch Surg 1989;124:933-6.

13 Andres JM, Mathias JR, Clench MH, Davis RH. Gastric emptying in infants with gastro-oesophageal reflux. Measurements with a Technitium-99m-labelled semisolid meal. Dig Dis Sci 1988;33:393-9.

14 Di Lorenzo C, Piepsz A, Ham H, Cadranel S. Gastric emptying with gastro-oesophageal reflux. Arch Dis Child 1987; 62:449-53.

15 Guillet J, Wynchank S, Christophe E, Basse-Cathalinat B, Ducassou D, Blanquet P. Gastro-oesophageal reflux and gastric emptying of liquids in paediatric patients. Int $\mathcal{Y}$ Nucl

16 Jolley SG, Leonard JC, Tunell WP. Gastric emptying in children with gastro-oesophageal reflux. 1. An estimate of
effective gastric emptying. $\mathcal{F}$ Paediatr Surg 1987; 22:923-6. 
17 Newell SJ, Chapman S, Booth IW. Ultrasonic assessment of gastric emptying in the preterm infant. Arch Dis Child 1993;69:F32-6

18 Ewer AK, Durbin GM, Morgan MEI, Booth IW. Gastric emptying in preterm infants. Arch Dis Child 1994;71:F24F7.

19 Georgieff MK, Hoffman JS, Pereira GR, Bernbaum J, Hoffman-Williamson $M$. Effect of neonatal caloric deprivation on head growth and 1-year developmental status in vreterm infants. $\Im$ Pediatr 1985;107:581-7.

20 Heacock HJ, Jeffery HE, Baker JL, Page M. Influence of breast versus formula milk on physiological gastrooesophageal reflux in healthy, newborn infants. $\mathcal{F}$ Paediatr Gastroenterol Nutr 1992;14:41-6.

21 Tolia V, Lin C-H, Kuhns LR, Gastric emptying using three different formulas in infants with gastro-oesophageal reflux. F Pediatr Gastroenterol Nutr 1992;15:297-301.

22 Newell SJ, Morgan MEI, Durbin GM, Booth IW, McNeish AS. Does mechanical ventilation precipitate gastrooesophageal reflux during enteral feeding? Arch Dis Child 1989;64:1352-5.
23 Sondheimer JM, Clark DA, Gervaise EP. Continuous gastric $\mathrm{pH}$ measurement in young and older preterm infants receiving formula and clear liquid feedings. $\mathcal{F}$ Pediatr Gastroenterol Nutr 1985;4:352-5.

24 Dodds WJ, Dent J, Hogan WJ, et al. Mechanisms of gastrooesophageal reflux in patients with reflux oesophagitis. $N$ Engl f Med 1982;307:1547-52.

25 Mahoney MJ, Migliavacca M, Spitz L, Milla PJ. Motor disorders of the oesophagus in gastro-oesophageal reflux. Arch Dis Child 1988;63:1333-8.

26 Cucchiara S, Santamaria F, Andreotti MR, Minella $R$, Ercolini P, Oggero V, et al. Mechanisms of gastroErcolini P, Oggero V, et al. Mechanisms of gastrooesophageal reflux

27 Stainio A, Cucchiara S, Del Giudice E, Andreotti MR, Minella R. Disorders of oesophageal motility in children with psychomotor retardation and gastro-oesophageal reflux. Eur $\mathcal{F}$ Pediatr 1991;150:638-41.

28 Omari TI, Kazunori M, Fraser R, et al. Esophageal body and lower esophageal sphincter function in healthy preterm infants. Gastroenterology 1995;109:1757-640. 